\title{
Subconjunctival Hemorrhage
}

National Cancer Institute

\section{Source}

National Cancer Institute. Subconjunctival Hemorrhage. NCI Thesaurus. Code C35045.

Blood between the conjunctiva and sclera. 